\title{
Rise-Up mist-netting (RUM): a mobile protocol for trapping wary territorial birds
}

\author{
Paulo Sérgio Amorim'; Mariana Fonseca Rossi' \& André de Camargo Guaraldo ${ }^{3}$
}

${ }^{1}$ Universidade Federal de Juiz de Fora (UFJF), Instituto de Ciências Biológicas (ICB), Departamento de Zoologia (DEPZO0), Laboratório de Ecologia Comportamental e Ornitologia (LECO), Programa de Pós-Graduação em Ciências Biológicas (Zoologia) - Comportamento e Biologia Animal (PPGCB-CBA). Juiz de Fora, MG, Brasil. ORCID: http://orcid.org/0000-0003-4979-8589. E-mail: paulo.amorim@icb.ufjf.br

${ }^{2}$ Universidade Federal de Juiz de Fora (UFJF), Instituto de Ciências Biológicas (ICB), Departamento de Zoologia (DEPZO0), Laboratório de Protozoologia (LABPROTO). Juiz de Fora, MG, Brasil. ORCID: http://orcid.org/0000-0001-7573-5544. E-mail: mfonsecarossi@gmail.com

${ }^{3}$ Universidade Federal de Juiz de Fora (UFJF), Instituto de Ciências Biológicas (ICB), Departamento de Zoologia (DEPZO0), Laboratório de Ecologia Comportamental e Ornitologia (LECO). Juiz de Fora, MG, Brasil. ORCID: http://orcid.org/0000-0003-1705-2926. E-mail: guaraldoac@gmail.com

\begin{abstract}
Many bird species avoid traditional traps such as mist nets, thus alternative trapping methods are often needed. The Rufous Hornero (Furnariidae: Furnarius rufus) is one such species that was captured so far using conventional mist netting in rural areas or using nest-targeted traps, which risk nest damage and abandonment. Here we describe the novel rise-up mistnetting (RUM) protocol and its catchability for the wary and territorial Rufous Hornero in an urban area. The RUM trap allowed us quickly capturing 40 Rufous Hornero individuals even in paved parking lots and streets during the bird's breeding period. The RUM is an active and targeted protocol that demands a single and quickly trainable field assistant. Therefore, it should also enable the capture of many understudied territorial but wary species. Moreover, it has enough mobility to fit studies in urban areas, and whenever researchers may deal with limited space and, at the same time, should reduce negative visual impacts to the general public of birds' capturing and banding procedures.
\end{abstract}

Keywords. Bird banding; Bird capture; Mist net; Targeted trapping; Urban ornithology.

\section{INTRODUCTION}

When studying bird ecology and their community interaction dynamics and behavioral adaptations to the urban environments, researchers often demand techniques to capture and mark individuals. Ornithologists developed many non-lethal capture methods, such as the classic mist net (Keyes \& Grue, 1982), but more sophisticated methods also exist, such as explosive-propelled (Dill \& Thornsberry, 1950) and compressed-air cannon nets (Bamford et al., 2009; Caudill et al., 2014), submerged mist nets (Breault \& Cheng, 1990), claptraps (Koopman \& Hulscher, 1979), flip nets (Adams et al., 2019), leg lasso (Herring et al., 2008; Adams et al., 2019), crossbow-net (Martins et al., 2014), pressure-operated drop net (Bush, 2008), above-water suspended mist net (Ware et al., 2013), and nest traps (Marvelde et al., 2011; Sousa \& Stewart, 2011; Braga et al., 2014). Many of these methods were improved through time to overcome the limited catchability of specific taxa such as those secretive or wary (Cerboncini et al., 2015), hummingbirds (Ruschi, 2009), large-bodied endangered species (Bush, 2008), and even to suit to challenging scenarios such as dense forest understory or wet areas (e.g., Pollock \& Paxton, 2006; Herring et al., 2008; Alza et al., 2017; Adams et al., 2019).

Mist nets remain one of the main bird capture methods among this variety of techniques (Heath \& Frederick, 2003; Dunn \& Ralph, 2004). Its popularity seems linked to the ease transportation, setting, and use (Keyes \& Grue, 1982; Heath \& Frederick, 2003), besides its feasibility in capturing a broad range of bird guilds (Dunn \& Ralph, 2004), irrespective of their territorial aggressiveness (Sogge et al., 2001, Cerboncini et al., 2015), and in distinct habitats (Lövei et al., 2001; Pollock \& Paxton, 2006; Adams et al., 2019). Despite the mist net versatility, its capture success varies among species as expected to any method (Wang \& Finch, 2002), thus demanding pilot studies for species-specific mesh size adjustments (Pardieck \& Waide, 1992; Piratelli, 2003), careful considerations on where to set the trap given birds flight path (Pagen et al., 2002; Heath \& Frederick, 2003; Smith et al., 2015; Alza et al., 2017), and planning according to the species phenology (Pagen et al., 2002), daytime and light incidence to reduce the trap visibility by birds (Keyes \& Grue, 1982). To lessen trapping difficulties and ensure capturability 
to a given methods, one may need protocol adjustments and improvements, such as the use of playbacks and/or decoys (Sogge et al., 2001; Heath \& Frederick, 2003; Efe \& Filippini, 2006; Covert-Bratland et al., 2007; Gill et al., 2007; Stutchbury et al., 2007; Massoni et al., 2012; Ware et al., 2013; Adreani et al., 2018).

The Rufous Hornero (Furnariidae: Furnarius rufus) is a Neotropical ovenbird species that inhabits open-vegetation habitats, including urban open-areas, able of becoming used to nearby humans (Fraga, 1980; Marreis \& Sander, 2006; Prestes et al., 2018). A previous study successfully captured this species using conventional targeted mist-netting in rural areas, often coupled with stuffed decoys and/or playbacks (Adreani et al., 2018). Nevertheless, the capture of this species in urban environments often faced adversities related to the detection and avoidance of mist nets (Bobato, 2012; Braga, 2012; Braga et al., 2014). To overcome such issue, researchers opt for trapping adults while nesting and nestlings (Bobato, 2012; Diniz et al., 2019) or to use baited cages (e.g., Braga, 2012; Shibuya, 2015). Here we describe a new protocol that combines playbacks to a single small $(6 \mathrm{~m})$ mist net handled in an innovative way for capturing Rufous Horneros during its breeding period.

\section{MATERIAL AND METHODS}

\section{Study site and Rufous Hornero capture challenges}

We run this study in anthropized areas at the Universidade Federal de Juiz de Fora campus and its surroundings $\left(21^{\circ} 46^{\prime} 37.0^{\prime \prime} \mathrm{S}, 43^{\circ} 22^{\prime} 08.3^{\prime \prime} \mathrm{W}\right)$. We initially set up to three conventional mist nets $(36 \mathrm{~mm}$ mesh, 9-12 $\mathrm{m}$ long, $3 \mathrm{~m}$ height, 5 shelves) to capture the only two Rufous Hornero that held territories that included unpaved areas. All such capture attempts failed, even when using playbacks as decoys. We were unable to set mist nets to try capturing any other birds at our study site since all of the remaining territories $(n=17)$ were alongside streets, within private properties, and at paved parking lots with continuous pedestrian and car traffic.

\section{Rise-up mist-netting (RUM) procedures}

To overcome the above-stated hindrances, we developed the "rise-up mist-netting" protocol (RUM; "Rede de neblina de elevação" in Portuguese; "red de niebla de elevación" in Spanish). The protocol uses a single short mist net $(6 \mathrm{~m}$ long, $2.5 \mathrm{~m}$ height, 4 shelves, $19 \times 19 \mathrm{~mm}$ mesh) anchored on two $2 \mathrm{~m}$ long 1" PVC pipes handled by the researcher and a field assistant. Upon usage, the mist net was set to the poles as it would be in the conventional protocol. Instead of having the poles anchored to the ground, the trap was transported by a single person, with the net held and the poles held together closed until the researcher spotted a target individual. When that happened, a wireless speaker was set $\sim 1 \mathrm{~m}$ behind the mist net. The net was stretched open horizontally on the

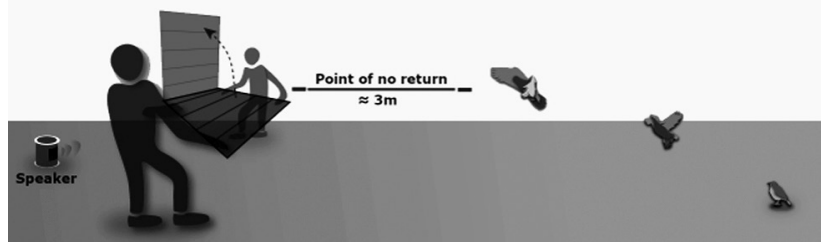

Figure 1. Schematics of the rise-up mist-netting (RUM) trapping protocol showing the $6 \mathrm{~m}$ long mist net setup between a wireless speaker and the targeted bird while being operated by the researcher and a single assistant. The pole extremity closer to the bird must be quickly and simultaneously raised upright by both operators only after the bird reaches the point-of-no-return (i.e., the point which the bird is unable to avoid colliding to the trap), which was estimated through trial-and-error to be $\sim 3 \mathrm{~m}$ for the Rufous Hornero (Furnarius rufus).

heist level ( $\sim 1 \mathrm{~m}$ above ground) and between the speaker and the targeted bird. Then, a capture attempt started by setting off a territorial playback. When the targeted individual flew towards the speaker, both operators coordinated a quick rise of the pole extremity closer to the bird, which often culminated in its capture (Fig. 1).

Capture effectiveness through RUM depended on a synchronized pole rising movement by the operators plus doing so only when the bird was too close to perform any evasive flight. This distance might vary according to the targeted species flight ability and defined through trial and error as $\sim 3 \mathrm{~m}$ for the Rufous Hornero. Finally, when the bird collided to the net, the operators held both poles upright to ensure the bird restrainment inside the net pocket and until one or both researchers reached and untangled it after gently retracting the net. To measure its efficiency, we run 28 days of capturing efforts using the RUM protocol during the Rufous Hornero pre-breeding ( $\mathrm{n}=8$ days in July 2019), breeding ( $\mathrm{n}=19$ days in August-November 2019), and non-breeding ( $n=1$ day in March) periods, during either mornings ( $n=6$; from 8 to 11 AM) and afternoons ( $n=21 ; 1$ to 6 PM).

\section{Data analysis}

As the RUM efficiency measure, we assumed the daily capture rate, controlled by effort in each period (e.g., captured bird per hour in a morning of a given day). We chose to do so as this is the only metric comparable to an existing dataset on this species (Adreani et al., 2018). A Wilcoxon test in $R$ version 4.0.0 ( $R$ Core Team, 2020) checked for differences in capture rates between mornings and afternoons. To avoid likely biases, we excluded the two captures made during the non-breeding period from the analysis. To check for any sex-related capture bias, we defined birds' sex by jointly considering their color band code and role in the couple's duet (Roper, 2005).

\section{RESULTS}

All attempts to capture Rufous Hornero pairs failed when using the conventional targeted mist netting (10 mist net.hr in 2 days). Birds always responded aggressive- 
ly to playbacks but flew low and straight to the speaker only until they noticed the mist net on their way, evading it by performing a quick U-turn flight. Sometimes, birds alternatively swerved over the net or even through its side. When running the RUM protocol, we successfully captured 38 Rufous Horneros, capturing an average of $1.4(S D=0.8)$ individual per day. We found no capturing rate differences between mornings and afternoons $(\mathrm{W}=74.5 ; \mathrm{p}=0.5)$.

The RUM protocol was the only trapping method that resulted in successful captures of Rufous Horneros at our study site. By using this protocol, we successfully captured juveniles ( $n=2$ females, 2 males, and 2 of unknown sex) and adults ( $\mathrm{n}=16$ males, 13 females, and 3 of unknown sex). Among all individuals established in our study area, some successfully avoided the trap ( $n=3$ females, 2 males, and 1 of unknown sex). On the other hand, the mobility given by the RUM protocol allowed us to capture at least one individual of each pair within 30 min after we spotted the individual. We only failed to capture any bird in two attempts, in a total of only $\sim 6 \mathrm{~h}$ of efforts during the breeding period (19 September and 11 October). The additional day of capture efforts during the non-breeding period (10 March 2020) resulted in two birds trapped in $2,5 \mathrm{~h}$. We noticed that releasing the first captured individual before capturing its mate often ended up in the latter avoiding the trap repeatedly $(n=10)$. Therefore, we found that whenever we held the first captured individual in a cloth bag, and only for up to 30 min due to ethical reasons, the other individual remained aggressive towards the playback, which ensured its capture as well $(n=9)$.

Throughout this study, multiple field assistants $(n=7)$ aided the lead author operating the RUM trap, which proves that the protocol is of ease training even for those assistants unfamiliar to mist nets $(n=5)$. Moreover, the RUM protocol was more time-efficient than the conventional mist-netting protocol: we set the entire apparatus to capture a spotted individual through RUM $\sim 75 \%$ faster than through the usual protocol ( 2 vs. $\sim 8 \mathrm{~min})$. Despite the quick training, capturing attempts failed whenever the two operators rose the pole asynchronously or made it too soon, i.e., when the bird was beyond the point-ofno-return. On top of that, escapes $(n=3)$ only occurred when operators failed to hold the net poles upright, i.e., tilted them back. Therefore, we realized it is paramount to collapse the mesh pocket trammel loops immediately after the bird collision. Whenever a Rufous Hornero individual managed to avoid the trap or escape from it, a new capture attempt required resetting the entire trap on a new site within the territory, which sometimes demanded taking a > 30 min break so birds would return to their previous foraging or perching site or even cease their vigilance. When none of these approaches succeeded, we took a $24 \mathrm{hr}$ break before a new attempt.

\section{DISCUSSION}

In this study, we show the successful results of capturing Rufous Hornero individuals using the new rise-up mist-netting (RUM) protocol. We developed the RUM protocol for improving the catchability of this and other birds that actively avoid passive mist nets but that are used to humans, especially in urban areas. In our field tests, we successfully captured 40 Rufous Hornero individuals using the RUM protocol during the pre-breeding, breeding, and non-breeding periods, in $<10 \mathrm{hr}$ of efforts.

Our initial attempts in capturing the Rufous Hornero confirmed that this species is hardly trapped (Bobato, 2012; Braga, 2012; Sabino, 2015). Previous successes in capturing the Rufous Hornero using conventional passive mist nets, either aided by playbacks (Massoni et al., 2012) or associated with a stuffed decoy (Adreani et al., 2018), ended up with a capture rate of $\sim 1.7 \pm 0.8$ individuals.day $^{-1}$ (Adreani et al., 2018). Other researchers had to develop or use alternative trapping methods, including a modified fish basket to capture adults leaving the nest during the egg incubation period (Braga et al., 2014) and a dog-food- or bread-baited bird cage trap to catch individuals while foraging on the ground (Bobato, 2012; Braga, 2012).

Yet useful, all such alternatives have drawbacks. First, waiting for a wary adult entering a baited cage trap may be tedious and time-consuming (Braga et al., 2014). Second, in urban areas, Rufous Hornero often builds their nests near or on electric power poles (Efe \& Filippini, 2006). This scenario describes almost half $(n=10)$ of the territories found at our study site, thus highlighting that the nest-oriented captures are often impractical and potentially life-risking. Third, nest-oriented traps always have the risk, though low, of permanently damaging the nest or even causing nest abandonment (Marvelde et al., 2011). Fourth, adults use their nests only while breeding. Therefore, there was currently no trap available for actively capturing adult and young individuals of this wary territorial bird during the breeding and non-breeding periods.

The RUM protocol contrasts with all existing protocols since it allowed us to capture the Rufous Hornero at a similar rate than the conventional passive netting protocol used in rural areas. Nevertheless, (i) it is a targeted and active capture method likely feasible for capturing other territorial ground-forager species used to humans and even in small and paved urban areas with pedestrian and car traffic; (ii) it is of quick assembling ( $2 \mathrm{~min})$; (iii) it allows mobility to researchers; (iv) it is suitable to urban environments; and ( $v$ ) it is especially valuable when researchers desire to avoid likely negative perceptions of citizens that may witness their bird capturing activities (e.g., Daily Mail, 2012; Shalders, 2018).

Training field assistants for running the RUM protocol revealed to be quick and easy, thus an additional positive aspect of this protocol. The main effort in this aspect was to synchronize the raising movement of both operators at the exact time when the bird reached the point-of-noreturn. Moreover, and despite beyond this study's goals, we unintentionally recaptured one Rufous Hornero individual, suggesting that RUM may circumvent the usual trap avoidance shown by birds after being captured for the first time (MacArthur \& MacArthur, 1974; Lövei et al., 2001). The capture of a Rufous Hornero couple during 
the non-breeding period also suggests RUM usefulness throughout the year for capturing this species. In particular, the RUM protocol should aid fostering studies on other ground foragers and/or on territorial species used to human presence that react to playbacks with a directed flight, such as the Great Kiskadee (Pitangus sulphuratus), the Fork-tailed Flycatcher (Tyrannus savana) and the Southern Lapwing (Vanellus chilensis).

By running the RUM protocol, we were captured and marked as much Rufous Hornero individuals as needed for developing an ongoing individual-based study on its territoriality. Thus, our focus lied on marking the study population, not in quantifying capture effort or rate. Nevertheless, we acknowledge that specific studies may require an upper-limit time until capture, such as those that involve some hormone level analysis (Adreani et al., 2018). In such scenarios, pilot samplings are mandatory for evaluating whether the RUM protocol is feasible, a cautionary note appliable to any other methods or protocols as all are subject to natural response variations by birds and even within species. By adding the RUM protocol to the field ornithologists' toolbox, we expect aiding further studies on the many understudied neotropical species that actively avoid the traditional mist-netting protocols and for which we still lack individual-level behavioral data, especially in urban areas.

\section{ACKNOWLEDGMENTS}

The authors thank ICMBio and CEMAVE for capturing and banding permits. The local ethics and animal care committee (CEUA-UFJF) approved the field procedures. This study was financed in part by the Coordenação de Aperfeiçoamento de Pessoal de Nível Superior - Brasil (CAPES) - Finance Code 001 and by the Association of Field Ornithologists with an E. Alexander Bergstrom Memorial Research Award. Authors are in debt to Lilian T. Manica and Miguel Â. Marini for providing some of the equipment and to the many volunteers who assisted with fieldwork, namely Fábio Palacio, Daniel Oliveira, Mariana Oliveira, Polônia Nunes, Lucas Morgado, Juliana Oliveira, and Clarissa Vidal. We also thank Pedro Diniz, Raphael Igor Dias and multiple anonymous reviewers who provided insightful comments in early versions of this manuscript.

\section{AUTHORS' CONTRIBUTIONS}

P.S.P.A., M.F.R., and A.C.G. have actively participated in designing the study and in collecting, analyzing and discussing the data, as well as approved the final version of the manuscript.

\section{REFERENCES}

Adams, H.; Murray, M.H.; Welch, C.; Kidd-Weaver, A.; Ellison, T.; Curry, S.; Hepinstall-Cymerman, J. \& Hernandez, S.M. 2019. Capturing American
White Ibises in urban South Florida using two novel techniques. Journal of Field Ornithology, 90(4): 373-381.

Adreani, N.M.; Goymann, W. \& Mentesana, L. 2018. Not one hormone or another: aggression differentially affects progesterone and testosterone in a South American ovenbird. Hormones and Behavior, 105: 104-109.

Alza, L.; Bautista, E.; Smith, M.; Gutierrez-Pinto, N.; Astie, A. \& Mccracken, K.G. 2017. Capture efficiency of torrent ducks by the active mist-net method. Wildlife Society Bulletin, 41(2): 370-375.

Bamford, A.J.; Monadjem, A.; Diekmann, M. \& Hardy, I.C.W. 2009. Development of Non-Explosive-Based Methods for Mass Capture of Vultures. South African Journal of Wildlife Research, 39(2): 202-208.

Bobato, R. 2012. Cuidado parental pós saída do ninho em João-de-barro (Furnarius rufus). (B.Sc. dissertation). Universidade Federal do Paraná, Curitiba.

Braga, T.V. 2012. 0 investimento em cuidado parental é igual entre os sexos em uma espécie monogâmica - Furnarius rufus? (Masters Dissertation). Universidade Federal do Paraná, Curitiba.

Braga, T.V.; Shibuya, F.L.; Cerboncini, R.A. \& Roper, J.J. 2014. An improved method for capturing cavity-nesting birds tested with the Rufous Hornero (Furnarius rufus). Ornitologia Neotropical, 25: 389-396.

Breault, A.M. \& Cheng, K.M. 1990. Use of submerged mist nets to capture diving birds. Journal of Field Ornithology, 61(3): 328-330.

Bush, K.L. 2008. A pressure-operated drop net for capturing Greater SageGrouse. Journal of Field Ornithology, 79(1): 64-70.

Caudill, D.; Caudill, G.; Meyer, K.D.; Kent, G.M.; Tarwater, J. \& Butler, E. 2014. A pneumatic net gun method for capture of Great Egrets (Ardea alba). Waterbirds, 37(4): 457-461.

Cerboncini, R.A.; Braga, T.V.; Roper, J.J. \& Passos, F.C. 2015. How to capture breeding Southern Lapwing Vanellus chilensis. Revista Brasileira de Ornitologia, 23(1): 1-4.

Covert-Bratland, K.A.; Theimer, T.C. \& Block, W.M. 2007. Hairy Woodpecker winter roost characteristics in burned ponderosa pine forest. The Wilson Journal of Ornithology, 119(1): 43-52.

Daily Mail. 2012. Not so free as a bird: Provocative pictures show species tangled up in ornithologists' mist nets. Daily Mail Online. Available: https://www. dailymail.co.uk/news/article-2181827/Provocative-pictures-speciestangled-ornithologists-mist-nets.html. Access: 10/08/2020.

Dill, H.H. \& Thornsberry, W.H. 1950. A cannon-projected net trap for capturing waterfowl. The Journal of Wildlife Management, 14(2): 132-137.

Diniz, P.; Macedo, R.H. \& Webster, M.S. 2019. Duetting correlates with territory quality and reproductive success in a suboscine bird with low extra-pair paternity. The Auk, 136(1): uky004.

Dunn, E.H. \& Ralph, C.J. 2004. The use of mist nets as a tool for bird population monitoring. Studies in Avian Biology, 29(1-6).

Efe, M.A. \& Filippini, A. 2006. Nidificação do joão-de-barro, Furnarius rufus (Passeriformes, Furnariidae) em estruturas de distribuição de energia elétrica em Santa Catarina. Ornithologia, 1(2): 121-124.

Fraga, R.M. 1980. The breeding of the Rufous Hornero (Furnarius rufus). Condor, 82: 58-68.

Gill, S.A.; Alfson, E.D. \& Hau, M. 2007. Context matters: female aggression and testosterone in a year-round territorial neotropical songbird (Thryothorus leucotis). Proceedings of the Royal Society B: Biological Sciences, 274(1622): 2187-2194.

Heath, J.A. \& Frederick, P.C. 2003. Trapping White Ibises with rocket nets and mist nets in the Florida Everglades. Journal of Field Ornithology, 74(2): 187-192.

Herring, G.; Gawlik, D.E. \& Beerens, J.M. 2008. Evaluating two new methods for capturing large wetland birds. Journal of Field Ornithology, 79(1): 102-110.

Keyes, B. \& Grue, C. 1982. Capturing birds with mist nets: a review. North American Bird Bander, 7(1): 2-14. 
Koopman, K. \& Hulscher, J. 1979. Catching waders with a 'wilsternet'. Wader Study Group Bulletin, 26: 10-12.

Lövei, G.; Csörgõ, T. \& Miklay, G. 2001. Capture efficiency of small birds by mist nets. Ornis Hungarica, 11: 19-25.

MacArthur, R.H. \& MacArthur, A.T. 1974. On the use of mist nets for population studies of birds. Proceedings of the National Academy of Sciences, 71(8): 3230-3233.

Marreis, I.T. \& Sander, M. 2006. Preferência ocupacional de ninhos de Joãode-barro (Furnarius rufus, Gmelin) entre área urbanizada e natural. Biodiversidade Pampeana, 4: 29-31.

Martins, R.C.; Catry, T. \& Granadeiro, J.P. 2014. Crossbow-netting: a new method for capturing shorebirds. Journal of Field Ornithology, 85(1): 84-90.

Marvelde, L.te; Webber, S.L.; van den Burg, A.B. \& Visser, M.E. 2011. A new method for catching cavity-nesting birds during egg laying and incubation. Journal of Field Ornithology, 82(3): 320-324.

Massoni, V.; Reboreda, J.C.; López, G.C. \& Aldatz, M.F. 2012. High coordination and equitable parental effort in the Rufous Hornero. The Condor, 114(3): 564-570.

Pagen, R.W.; Thompson III, F.R. \& Burhans, D.E. 2002. A comparison of pointcount and mist-net detections of songbirds by habitat and time-ofseason. Journal of Field Ornithology, 73(1): 53-59.

Pardieck, K. \& Waide, R.B. 1992. Mesh size as a factor in avian community studies using mist nets. Journal of Field Ornithology, 63(3): 250-255.

Piratelli, A. 2003. Mesh size and bird capture rates in Mato Grosso do Sul State, Brazil. Brazilian Journal of Biology, 63(1): 105-111.

Pollock, M.G. \& Paxton, E.H. 2006. Floating mist nets: a technique for capturing birds in flooded habitat. Journal of Field Ornithology, 77(3): 335-338.

Prestes, T.V.; Manica, L.T. \& Guaraldo, A.C. 2018. Behavioral responses of urban birds to human disturbance in urban parks at Curitiba, Paraná (Brazil). Revista Brasileira de Ornitologia, 26(2): 77-81.
Roper, J.J.2005. Sexually distinct songs in the duet of the sexually monomorphic Rufous Hornero (Diferenças sexuais nos cantos de dueto da espécie monomórfica Furnarius rufus). Journal of Field Ornithology, 234-236.

Ruschi, P.A. 2009. A new hummingbird trap. Boletim do Museu de Biologia Mello Leitão, 25: 67-75.

Sabino, U. 2015. Área de vida e comportamento de cuidado parental do Furnarius rufus (João-de-barro). (Masters Dissertation). Universidade Federal do Mato Grosso, Cuiabá, MT.

Shalders, A. 2018. Ativistas destroem experimento científico para libertar pássaros na llha Grande. BBC News Brasil. Available: https://www.bbc. com/portuguese/brasil-44556296. Access: 10/08/2020.

Shibuya, F.L.S. 2015. O ninho de João-de-barro (Furnarius rufus) éuma câmara de incubação. (Masters Dissertation). Universidade Federal do Paraná, Curitiba.

Smith, C.M.; Trimper, P.G.; Bate, L.J.; Brodeur, S.; Hansen, W.K. \& Robert, M. 2015. A mist-net method for capturing Harlequin ducks on rivers. Wildlife Society Bulletin, 39(2): 373-377.

Sogge, M.K.; Owen, J.; Paxton, E.H. \& Langridge, S. 2001. A targeted mist-net capture technique for the willow flycatcher. Western Birds, 32: 167-172.

Sousa, B.F. \& Stewart, S.L. 2011. Design and effectiveness of a novel trap for capturing nesting songbirds. Journal of Field Ornithology, 82(4): 425-429.

Stutchbury, B.J.; Morton, E.S. \& Woolfenden, B. 2007. Comparison of the mating systems and breeding behavior of a resident and a migratory tropical flycatcher. Journal of Field Ornithology, 78(1): 40-49.

The R Project for Statistical Computing (R Core Team). 2020. R: A language and environment for statistical computing. Vienna, R Foundation for Statistical Computing.

Wang, Y. \& Finch, D.M. 2002. Consistency of mist netting and point counts in assessing landbird species richness and relative abundance during migration. The Condor, 104(1): 59-72.

Ware, L.L.; Naumann, B.T.; Wilson, P.L.; Petrie, S.A. \& Schummer, M.L. 2013. A lift-net method for capturing diving and sea ducks. Wildlife Society Bulletin, 37(4): 877-880. 